\title{
SARS-CoV-2 (COVID-19) serology: implications for clinical practice, laboratory medicine and public health
}

\author{
Paul Van Caeseele MD, for the Canadian Public Health Laboratory Network; Dana Bailey MSc PhD, for the \\ Canadian Society of Clinical Chemists; Sarah E. Forgie MD MEd, for the Association of Medical Microbiology \\ and Infectious Disease Canada; Tanis C. Dingle PhD, for the Canadian Association for Clinical Microbiology and \\ Infectious Diseases; Mel Krajden MD, for the COVID-19 Immunity Task Force
}

Cite as: CMAJ 2020 August 24;192:E973-9. doi: 10.1503/cmaj.201588; early-released August 4, 2020

A complete list of the members of the 5 authorship groups appears at the end of the article.

linical presentation in persons infected with severe acute respiratory syndrome coronavirus 2 (SARS-CoV-2) ranges from asymptomatic to the life-threatening respiratory distress that can occur with coronavirus disease 2019 (COVID-19). ${ }^{1}$ Diagnosis of acute or new cases of SARS-CoV-2 infection at present relies upon molecular-based detection of viral RNA in upper or lower respiratory tract specimens, typically within 2-7 days after exposure..$^{2,3}$ In this period, active viral shedding occurs, and individuals who are infected can transmit the virus to others. Although viral RNA may still be detected in respiratory and stool specimens of some people for many weeks after they have recovered, this does not appear to pose a transmission risk. ${ }^{4,5}$ Serological testing involves detection of antibodies specific to SARS-CoV-2 infection in blood, serum or plasma. The role of serology is limited in the diagnosis of acute COVID-19 because it usually takes a minimum of 7-14 days or more after symptom onset to develop a reliable and measurable SARS-CoV-2 antibody response. ${ }^{6,7}$ However, interest has arisen in the potential application of serological testing for purposes as wideranging as authorization of international travel, stratification of reinfection risk in workplaces and the reduction of public anxiety to facilitate resumption of economic activity. ${ }^{8,9}$ We review what is currently known regarding SARS-CoV-2 serological testing - a body of basic and clinical science that is still evolving (Box 1); consider its implications for clinical care, the development of appropriate services and test interpretation; and advise on appropriate use of serological testing for clinical and public health purposes.

\section{What are the antibody responses to SARS-CoV-2?}

The SARS-CoV-2 genome encodes 4 major structural proteins: surface or spike glycoprotein (S), envelope, membrane and nucleocapsid (N). ${ }^{10}$ Currently available serological tests detect antibodies to various epitopes on the S or $\mathrm{N}$ structural proteins.

\section{KEY POINTS}

- Multiple commercial assays for severe acute respiratory syndrome coronavirus 2 (SARS-CoV-2) antibodies have been approved for use as serological tests by Health Canada, with some manufacturers claiming about $95 \%$ sensitivity and about $99.5 \%$ specificity.

- The detectable presence of SARS-CoV-2 antibodies has not yet been proven to confer meaningful or durable immunity to reinfection. Thus, serological testing should not be used to guide individual decisions about personal or occupational exposures, use of personal protective equipment and physical distancing.

- At present, clinical indications for serologic testing in health care settings are limited, and SARS-CoV-2 serological testing has no role in routine clinical care.

- Serological testing at this time should be focused on research concerning immunity to SARS-CoV-2 and population-level studies to inform public health responses to the Canadian coronavirus disease 2019 (COVID-19) epidemic.

The surface spikes are the "corona" observed on electron micrographs of coronaviruses; they play a critical role in viral pathogenesis, and thus studies have focused on antibodies to specific parts of the $S$ glycoprotein. Each spike protein consists of 2 subunits: the S1 subunit binds to angiotensin-convertingenzyme-2 receptors on cells in multiple organs via its receptorbinding domain; and the S2 subunit mediates fusion between the virus and the cell membrane of the host. The $\mathrm{S}$ protein receptor-binding domain is an important vaccine and therapeutic target because a subset of antibodies targeting the receptorbinding domain appear to block viral binding and neutralize viral infectivity in vitro. ${ }^{11,12}$ 


\section{Box 1: Evidence used in this review}

We searched PubMed for articles published from Jan. 1, 2020, to June 30, 2020, in English on severe acute respiratory syndrome coronavirus 2 (SARS-CoV-2), immune response, diagnostics and serology with the following medical subject headings terms: coronavirus disease 2019 (COVID-19), antibodies, serology, serologic test, diagnosis, point-of-care testing, immunoglobulin, immunoassay, enzyme-linked immunosorbent assay, immunity, humoral, cross-reaction, neutralization assay and multisystem inflammatory syndrome in children.

We identified additional articles through weekly searches of the LitCOVID database under the categories of "mechanism" and "diagnosis" from Mar. 15, 2020, to June 30, 2020.

We also identified relevant studies by consulting with Canadian experts and searching COVID-19 and SARS-CoV-2 preprints in medRxiv and bioRxiv. In addition, we regularly consulted the relevant guidelines and resources from international organizations including the World Health Organization, Health Canada, Public Health Agency of Canada, US Food and Drug Administration, US Centers for Disease Control and Prevention and Infectious Diseases Society of America, along with guidance generated by the participating Canadian organizations.

Figure 1 shows a schematic of the pattern of antibody response to SARS-CoV-2 infection. Although immunoglobulin $M$ (IgM) and immunoglobulin A (IgA) antibodies are widely regarded to appear early during most acute viral infections, it is uncertain whether this occurs with SARS-CoV-2 infection. ${ }^{13}$ With COVID-19, similar to SARS and Middle East respiratory syndrome (MERS), both IgM and IgG antibodies appear at detectable levels concom- itantly around 2-3 weeks after symptom onset or exposure. .,7,14,15 $^{-1}$ However, in some mild and asymptomatic cases, antibodies may not be detected at all, at least within the time scale as reported in some recent studies ( $<46 \mathrm{~d}) .{ }^{15-17}$

Commercially available assays target 1 or more of the 3 antibody isotypes (i.e., IgA, IgM or IgG) or total immunoglobulin. The 2 main types of commercial assays are described in Box 2. An updated list of approved clinical diagnostic tests for SARS-CoV-2 antibodies is available through the Health Canada website. ${ }^{20}$ Although several laboratory-based immunoassays have been approved, there is insufficient evidence to support use of pointof-care testing devices for SARS-CoV-2 serology (see Box 2 for a description of these kits) and, at the time of writing, no SARSCoV-2 serological point-of-care tests have received Health Canada approval for use. ${ }^{19}$ Effective use and interpretation of pointof-care tests will require consistent correlation of their results with approved laboratory-based tests, as well as secure supplies of kits that have consistent quality-assured performance.

\section{What considerations affect the interpretation of SARS-CoV-2 serological tests?}

\section{Sensitivity, specificity and disease prevalence}

The discriminative potential of a test is assessed by its clinical sensitivity and specificity. The sensitivity is a measure of the test's ability to detect antibodies in matrices such as blood, serum or plasma of patients with SARS-CoV-2 infection (i.e., a true positive result). Specificity, on the other hand, is a measure of the test's ability to correctly identify the absence of antibodies

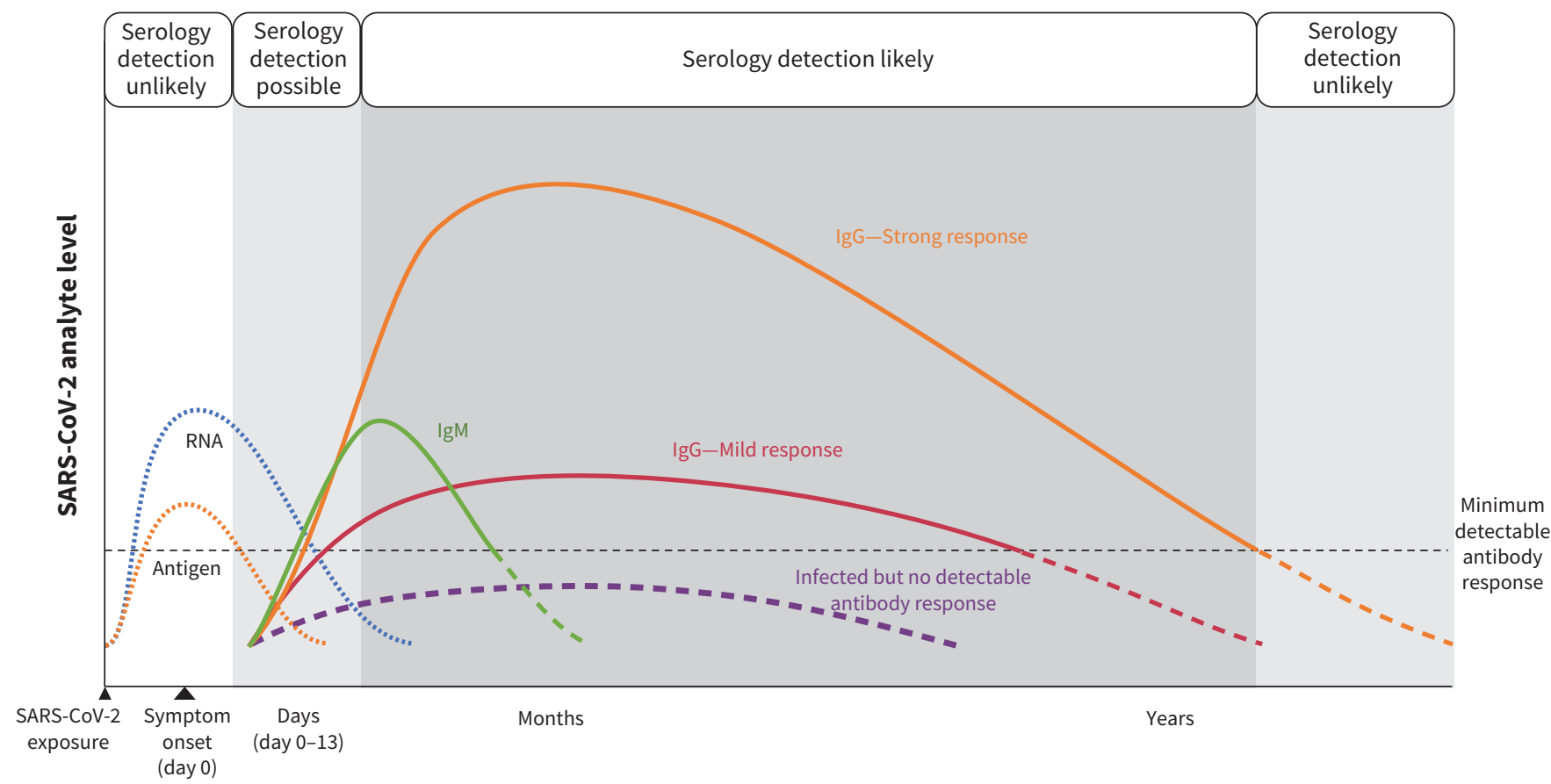

Figure 1: Description and projection for the kinetics of antibody response to infection caused by severe acute respiratory syndrome coronavirus 2 (SARS-CoV-2). With only a few months of experience to date, projections into years, although based on experience with other coronaviruses, must be regarded as speculative. Data on immunoglobulin A (IgA) responses are still emerging. Note: IgM = immunoglobulin M, IgG =immunoglobulin G. 
in an individual who has not been infected (i.e., a true negative result). At present, Health Canada recommends a target specificity of $98 \%$ or higher, and the minimum required for consideration of approval is $95 \% .{ }^{21}$ Sensitivity and specificity are inherent elements of test performance, but the predictive value of any test depends on the prevalence of the infection within a given population. For example, if the disease prevalence in the popula-

Box 2: Approaches to detecting antibodies for severe acute respiratory syndrome coronavirus 2

\section{Testing matrices}

- The tests listed here are typically used to detect antibody in blood sources.

- Laboratory-based immunoassays and specialized neutralization tests rely on blood matrices (serum or plasma). Point-of-care tests use blood from finger pricks (or heel pricks as applicable).

- Finger pricks can also be used to create dried blood spots that can be conveniently transported for laboratory-based immunoassays. Early results for dried blood spot testing results are promising, but insufficient evidence currently exists to support dried blood spot testing for severe acute respiratory syndrome coronavirus 2 (SARS-CoV-2). Comprehensive validation against results of tests based on venipuncture blood draws is ongoing worldwide.

- The consistency and interpretation of antibody detection from sources other than blood, such as saliva, is still uncertain.

\section{Types of tests}

- Laboratory-based immunoassays involve plate-based tests (enzyme-linked immunosorbent assays [ELISAs]) or chemiluminescent immunoassays (CLIAs) on automated highthroughput instruments. With most immunoassays, the signal produced by the assay correlates with the level of antibody detected in the patient's sample. Cross-reactions with other coronaviruses are uncommon but do occur. For laboratory-based tests, venipuncture and transport to the testing laboratory is typically required. Commercially available immunoassays are semiquantitative (i.e., use a cut-off to determine reactive [positive] versus nonreactive [negative] results).

- Rapid test cassettes or lateral flow tests are often referred to as point-of-care tests. These tests are typically easy to use, require only a small amount of blood matrix (e.g., from a finger prick), do not require specialized equipment or expertise and have rapid turnaround times (10-15 min). ${ }^{18}$ Most can detect immunoglobulin $M$ and immunoglobulin $\mathrm{G}$ separately or in combination. However, such assays are qualitative, performance varies substantially and none have been approved by Health Canada to date. There is no current indicated use for point-of-care tests. ${ }^{19}$

- Neutralization tests are considered the gold standard for antibody detection because of their high sensitivity and specificity but are not widely available. Laboratory-based and point-of-care immunoassays are "binding antibody assays" (i.e., they detect binding of antibody from patient blood to SARSCoV-2 antigens). In contrast, neutralization assays measure antibody-mediated inhibition of viral entry into cells in vitro. These tests require specialized expertise and laboratory containment facilities (containment level 3 for SARS-CoV-2), and have limited throughput. However, pseudovirus-based neutralization assays can detect neutralizing antibody to SARSCoV-2 using engineered noninfectious virus strains and can be performed in containment level 2 laboratories. tion is only $1 \%$, even a highly specific diagnostic test (99\% specificity or only 1 false-positive result out of 100 patient results) would be predicted to lead to roughly 1 false-positive result for every true positive result. ${ }^{9,22}$

In Canada, the baseline prevalence of SARS-CoV-2 infection as of July 9, 2020, was estimated at $0.3 \%$, based on 106805 confirmed cases of COVID-19. ${ }^{23}$ However, the number of Canadians infected is likely many times higher than indicated by the number of confirmed cases for several reasons. Current nucleic acid testing has moderate sensitivity, and tests performed in patients with infection may have returned a negative result in some cases. Furthermore, testing indications and coverage have varied over time and by region, and some people with SARS-CoV-2 infection do not show symptoms; therefore, many people who were infected may not have requested or qualified for testing. The prevalence of asymptomatic infection measured in other jurisdictions ranges widely depending on the target population tested, geographic location and age of the patients. ${ }^{14,24-27}$

We posit that the prevalence in most Canadian locations is likely low enough that very small reductions in test specificity will drive up the proportion of false positives that are reported. This can be corrected post hoc in population-level estimates of the prevalence of SARS-CoV-2 infections but creates problems in applying serology results at the individual level - a challenge compounded by biological uncertainties.

\section{Correlation of SARS-CoV-2 antibodies with virus neutralization}

Commercially available serological assays detect and semiquantitatively determine the amount of antibody binding to various SARS-CoV-2 antigens. (Quantitation may be valuable when a rising level suggests recent infection and associated positive seroconversion.) Depending on the antigen target used, the bound antibodies detected may correlate with detection of neutralizing antibodies that, as noted above, are antibodies that block viral binding and neutralize viral infection in vitro (hence the term, neutralizing antibodies). Neutralizing antibodies may provide a better indication of immunity, but there is ongoing debate as to whether neutralizing antibodies are the primary mechanism of immune protection against SARS-CoV-2 infection. ${ }^{22,28-30}$ Instead, a cell-mediated immune response, known to be a key element in viral control for SARSCoV-1 and MERS-CoV, ${ }^{31-33}$ may be more relevant. Therefore, further studies are required to evaluate the correlation of commercial assays for SARS-CoV-2 antibodies with neutralization capacity, the potential for antibody-dependent cell-mediated immune responses and seroprotection. . $^{34,35}$

\section{Duration of antibody response}

In mild and asymptomatic cases, antibody responses may not consistently develop or reach levels sufficient to be detectable by antibody tests. ${ }^{36}$ Research continues on the extent and duration of antibody responses in the context of infections ranging from asymptomatic to severe, and across different populations, ages, genetic backgrounds and comorbidities. Antibody levels to 
coronaviruses diminish over time. ${ }^{37,38}$ Persistence of measurable neutralizing antibodies for at least a year has been reported in patients who have recovered from MERS-CoV and SARS-CoV-1 illness, despite declines in titres. ${ }^{39,40}$ However, studies evaluating the immunological response to SARS-CoV-2 have suggested that a substantial proportion of asymptomatic patients are IgG negative during the convalescent phase of infection, ${ }^{36}$ and evidence is emerging that neutralizing antibodies to SARS-CoV-2 decrease in convalescent patients within 2-3 months after infection. ${ }^{36,41}$ In contrast, multiyear persistence of memory T-cell responses has been reported for both MERS-CoV and SARS-CoV-1, ${ }^{32,33}$ which suggests that waning antibody titres may not portend loss of immunity. The relation between measured antibodies and durability of protection therefore remains unclear.

\section{Serological test positivity and infectiousness}

A positive antibody result cannot be equated to a noninfectious state. Particularly for non-neutralizing antibodies, the presence of antibodies does not preclude active viral shedding through respiratory secretions. ${ }^{42,43}$ Thus, factors such as symptom onset, symptom resolution and days since onset or resolution should guide advice on infectivity.

\section{What are the implications for practitioners and policy-makers?}

\section{Consider test performance}

Laboratories should strive to implement SARS-CoV-2 serologic tests that have manufacturer-claimed sensitivity of $95 \%$ or more and specificity of $99.5 \%$ or more based on specimens obtained 14 days or more after onset of symptoms or a positive result for an RNA test. Serological testing in a real-world setting is necessary to confirm that the tests perform as claimed. To maximize specificity in populations with low pretest probability of disease (i.e., low community prevalence), it may be necessary to use orthogonal testing so that those patients with a positive result for 1 test are routinely retested with a second test to confirm the result.

When interpreting serological results, laboratories may need to consider time since onset of symptoms or time since exposure to SARS-CoV-2, if they are known. Clinical laboratories and ordering physicians also need to consider the pretest probability of a positive or negative result given the testing location and patient population (e.g., higher likelihood of a positive result in a hospital setting versus an outpatient seroprevalence screen).

Additional research studies of the performance of serology tests will be required with individuals in different age groups, at different times after exposure and to determine duration of detectable antibody after infection.

\section{When and who to test}

At present, use of SARS-CoV-2 serological testing should focus on informing the public health response to the Canadian epidemic rather than on estimating any individual's current or future susceptibility to infection. Serological testing should be reserved primarily for clinical research and population-level assessments of the prevalence of past infection with SARS-CoV-2.
Box 3: Use of serology in suspected multisystem inflammatory syndrome in children and adolescents temporally related to coronavirus disease 2019

- Case definitions for multisystem inflammatory syndrome in children (MIS-C) have been outlined by several organizations including the World Health Organization, Centers for Disease Control and Prevention, Royal College of Paediatrics and Child Health in the United Kingdom and the Canadian Paediatric Society, ${ }^{48-51}$ and include the use of severe acute respiratory syndrome coronavirus 2 (SARS-CoV-2) serology.

- Case series have reported high percentages of patients with positive results for SARS-CoV-2 serology testing, with lower rates of positivity for throat swabs and stool samples on polymerase chain reaction testing. ${ }^{52-54}$

- Several Canadian provinces are in the process of adopting these case criteria and have identified MIS-C as a notifiable disease, which requires case reporting to local public health authorities. ${ }^{55-57}$

- Despite the inclusion of serological testing in the MIS-C case definitions, the performance of serological tests in children and in patients with MIS-C remains poorly characterized.

- More studies are needed, including validation studies of SARSCoV-2 antibody assays in children and in suspected MIS-C.

As outlined previously, serological testing is neither adequate nor appropriate for use as the primary tool for diagnosis of infection or confirmation of noninfectivity. In other words, the current state of knowledge would not support having broadly available SARS-CoV-2 antibody tests. In the absence of a positive RNA test or evidence of seroconversion (as measured by a rising antibody level over time), serology should not be used to diagnose acute SARS-CoV-2 infection. On rare occasions, serological testing may be useful as an adjunct diagnostic test when molecular testing is repeatedly negative but clinical suspicion is high and symptoms persist. ${ }^{7,13,44-46}$ In such cases, the time since exposure (if known) or since symptom onset should be considered as seropositivity occurs only $7-14$ or more days after symptom onset.

Serological testing may assist in the assessment of patients who present with atypical clinical manifestations such as inflammatory syndromes (e.g., multisystem inflammatory disorder in children and adolescents, COVID toes or unexplained thrombosis). ${ }^{47,48}$ Box 3 discusses antibody testing in the context of multisystem inflammatory syndrome in children and adolescents, based on limited current evidence. . $^{13,49-54}$

\section{How to report the results of serological tests}

A recent United Kingdom report ${ }^{58}$ showed variability in the clinical interpretation of SARS-CoV-2 serology results especially with respect to inferring immunity and the infectious status of individuals. Consistent messaging and avoiding misinterpretation of serology test results depends on harmonized reporting across laboratories combined with proactive communication by laboratory staff, medical microbiologists and infectious disease practitioners. Box 4 provides suggestions for some interpretive wording for interim use by clinical and public health laboratories for reporting SARS-CoV-2 serology. 
Box 4: Suggestions for the reporting of test results by clinical laboratories (include as appended comments)

\section{Reporting positive/reactive results}

- Presence of severe acute respiratory syndrome coronavirus 2 (SARS-CoV-2) antibody indicates current or previous infection. False-positive results may occur because of cross-reacting antibody or other causes. Currently, it is unknown whether antibodies indicate protective immunity and for how long.

- Presence of SARS-CoV-2 antibody should not be used to infer the infectious status of an individual or immunity.

\section{Reporting negative/nonreactive results}

- Nonreactive results do not rule out acute or previous SARSCoV-2 infection.

- Absence of SARS-CoV-2 antibody should not be used to infer the infectious status of an individual or immunity.

Reporting inconclusive/indeterminate results

- An inconclusive result neither rules in nor rules out previous SARS-CoV-2 infection.

\section{Potential uses of SARS-CoV-2 serology from a public health and research perspective}

At present, based on the evidence we have considered, serological test results should not be used to guide patient-level decision-making on measures for infection control, including the use of personal protective equipment, timing of return to work or local physical-distancing policies.

However, seroprevalence studies of SARS-CoV-2 may be used to estimate rates of exposure and the geographic transmission of the virus within communities and populations, as well as within facilities, workplaces and households over time. This information may be used by epidemic modellers to help guide public health policies, by vaccine program planners to help set priorities and by front-line public health practitioners to determine which communities or congregate settings show minimal past exposure to SARS-CoV-2 and, therefore, may be at higher risk of rapid spread. At the interface of clinical and public health applications, while the diagnostic role of antibody testing is strictly adjunctive, seroprevalence studies may be useful in contact tracing when RNA tests are indeterminate.

Longitudinal seroprevalence studies may provide information on the nature and durability of antibody responses in patients with confirmed infection. The aim of such studies may be to determine if previous COVID-19 infection and seropositivity is associated with protection from subsequent reinfection; specialized serology tests, such as neutralization assays, will be particularly useful in this context. Likewise, serological screening of donated blood may reveal which blood samples contain adequate levels of neutralizing antibody to allow for their use in randomized controlled trials that investigate the effectiveness of pooled convalescent plasma treatment for patients with severe COVID-19.

Studies of vaccine effectiveness for SARS-CoV-2 may use serological testing results as a marker of immunity in cohort studies that explore correlates of protection and reinfection risk.

\section{Conclusion}

Given measurement and interpretive uncertainties of the tests, the clinical indications for SARS-CoV-2 serological testing are limited, with only a few exceptions. The tests will be useful in diverse research contexts and for policy-making in public health but should not be rolled out for general clinical use based on current evidence. Careful interpretation and reporting of test results is important. The current state of knowledge does not permit definitive inferences about immunity and likelihood of reinfection based on the results of serological testing, and testing cannot, therefore, be used to inform individuallevel decisions on changing occupational exposure, the use of personal protective equipment, recommendations on physical distancing by members of the public or advice on international travel.

\section{References}

1. Garg S, Kim L, Whitaker M, et al. Hospitalization rates and characteristics of patients hospitalized with laboratory-confirmed coronavirus disease $2019-$ COVID-NET, 14 States, March 1-30, 2020. MMWR Morb Mortal Wkly Rep 2020;69: 458-64.

2. Woloshin S, Patel N, Kesselheim AS. False negative tests for SARS-CoV-2 infection - challenges and implications. N Eng J Med 2020 June 5 [Epub ahead of print]. doi: 10.1056/NEJMp2015897.

3. To KK-W, Tsang OT-Y, Leung W-S, et al. Temporal profiles of viral load in posterior oropharyngeal saliva samples and serum antibody responses during infection by SARS-CoV-2: an observational cohort study. Lancet Infect Dis 2020;20:565-74.

4. Bullard J, Dust K, Funk D, et al. Predicting infectious SARS-CoV-2 from diagnostic samples. Clin Infect Dis 2020 May 22 [Epub ahead of print]. doi: 10.1093/ cid/ciaa638.

5. Zhou B, She J, Wang Y, et al. The duration of viral shedding of discharged patients with severe COVID-19. Clin Infect Dis 2020 Apr. 17 [Epub ahead of print]. doi: $10.1093 /$ cid/ciaa451.

6. Sun B, Feng $Y$, Mo $X$, et al. Kinetics of SARS-CoV-2 specific IgM and IgG responses in COVID-19 patients. Emerg Microbes Infect 2020;9:940-8.

7. Zhang G, Nie S, Zhang Z, et al. Longitudinal change of SARS-CoV2 antibodies in patients with COVID-19. J Infect Dis 2020 May 2 [Epub ahead of print]. doi: 10.1093/infdis/jiaa229.

8. Kofler N, Baylis F. Ten reasons why immunity passports are a bad idea. Nature 2020;581:379-81.

9. Weinstein MC, Freedberg KA, Hyle EP, et al. Waiting for certainty on COVID-19 antibody tests - At what cost? N Eng J Med 2020 June 5 [Epub ahead of print]. doi: 10.1056/NEJMp2017739.

10. Jiang S, Hillyer C, Du L. Neutralizing antibodies against SARS-CoV-2 and other human coronaviruses [published erratum in Trends Immunol 2020;41:545]. Trends Immunol 2020;41:355-9.

11. Wu Y, Wang F, Shen C, et al. A noncompeting pair of human neutralizing antibodies block COVID-19 virus binding to its receptor ACE2. Science 2020;368: 1274-8.

12. Ju B, Zhang Q, Ge J, et al. Human neutralizing antibodies elicited by SARSCoV-2 infection. Nature 2020 May 26 [Epub ahead of print]. doi: 10.1038/ s41586-020-2380-z.

13. Interim guidelines for COVID-19 antibody testing: interim guidelines for COVID19 antibody testing in clinical and public health settings. Atlanta: Centers for Disease Control and Prevention. Available: www.cdc.gov/coronavirus/2019 -ncov/lab/resources/antibody-tests-guidelines.html (accessed 2020 June 5).

14. Bryan A, Pepper G, Wener MH, et al. Performance characteristics of the Abbott Architect SARS-CoV-2 IgG assay and seroprevalence in Boise, Idaho. J Clin Microbiol 2020 May 7 [Epub ahead of print]. doi: 10.1128/JCM.00941-20.

15. Yongchen Z, Shen H, Wang X, et al. Different longitudinal patterns of nucleic acid and serology testing results based on disease severity of COVID-19 patients. Emerg Microbes Infect 2020;9:833-6. 
16. Liu Z-L, Liu Y, Wan L-G, et al. Antibody profiles in mild and severe cases of COVID-19. Clin Chem 2020 June 10 [Epub ahead of print]. doi: 10.1093/ clinchem/hvaa137.

17. Long Q-X, Liu B-Z, Deng H-J, et al. Antibody responses to SARS-CoV-2 in patients with COVID-19. Nat Med 2020;26:845-8.

18. Yip PM, Venner AA, Shea J, et al. Point-of-care testing: a position statement from the Canadian Society of Clinical Chemists. Clin Biochem 2018;53:156-9.

19. Respiratory Virus Infections (ReVI) Working Group. The Canadian Public Health Laboratory Network (CPHLN) statement on point-of-care serology testing in COVID-19. Canadian Association for Clinical Microbiology and Infectious Diseases; 2020. Available: www.cacmid.ca/wp-content/uploads/ReVi-Position-Statement -on-POC-Serology-v1.00.pdf (accessed 2020 June 30).

20. Authorized medical devices for uses related to COVID-19: list of authorized testing devices. Ottawa: Health Canada; modified 2020 July 14. Available: www.canada.ca/en/health-canada/services/drugs-health-products/covid19 -industry/medical-devices/authorized/list.html\#wb-auto-5 (accessed 2020 July 6).

21. COVID-19 serological testing devices: Notice on sensitivity and specificity values. Ottawa: Health Canada; 2020 June 24, modified June 25. Available: www. canada.ca/en/health-canada/services/drugs-health-products/covid19-industry /medical-devices/testing/serological/notice-sensitivity-specificity-values.html (accessed 2020 July 8).

22. Bryant JE, Azman AS, Ferrari MJ, et al. Serology for SARS-CoV-2: apprehensions, opportunities, and the path forward. Sci Immunol 2020;5:eabc6347.

23. Coronavirus disease (COVID-19): Outbreak update. Ottawa: Public Health Agency of Canada; modified 2020 July 11. Available: www.canada.ca/en/public -health/services/diseases/2019-novel-coronavirus-infection.html\#a1 (accessed 2020 July 9).

24. Mizumoto K, Kagaya K, Zarebski A, et al. Estimating the asymptomatic proportion of coronavirus disease 2019 (COVID-19) cases on board the Diamond Princess cruise ship, Yokohama, Japan, 2020. Euro Surveill 2020;25:2000180.

25. Nishiura H, Kobayashi T, Suzuki A, et al. Estimation of the asymptomatic ratio of novel coronavirus infections (COVID-19). Int J Infect Dis 2020;94:154-5.

26. Qiu H, Wu J, Hong $L$, et al. Clinical and epidemiological features of 36 children with coronavirus disease 2019 (COVID-19) in Zhejiang, China: an observational cohort study. Lancet Infect Dis 2020;20:689-96.

27. Global serological knowledge hub: SeroTracker. Montréal: COVID-19 Immunity Task Force. Available: www.covid19immunitytaskforce.ca/research/global -serological-knowledge-hub/ (accessed 2020 June 20).

28. Cao Y, Su B, Guo X, et al. Potent neutralizing antibodies against SARS-CoV-2 identified by high-throughput single-cell sequencing of convalescent patients' B cells. Cell 2020;182:73-84.e16.

29. Chandrashekar A, Liu J, Martinot AJ, et al. SARS-CoV-2 infection protects against rechallenge in rhesus macaques. Science 2020 May 20 [Epub ahead of print]. doi: 10.1126/science.abc4776.

30. Kirkcaldy RD, King BA, Brooks JT. COVID-19 and postinfection immunity: limited evidence, many remaining questions. JAMA 2020 May 11 [Epub ahead of print]. doi: 10.1001/jama.2020.7869.

31. Channappanavar R, Zhao J, Perlman S. T cell-mediated immune response to respiratory coronaviruses. Immunol Res 2014;59:118-28.

32. Ng O-W, Chia A, Tan AT, et al. Memory T cell responses targeting the SARS coronavirus persist up to 11 years post-infection. Vaccine 2016;34:2008-14.

33. Channappanavar R, Fett C, Zhao J, et al. Virus-specific memory CD8 T cells provide substantial protection from lethal severe acute respiratory syndrome coronavirus infection. J Virol 2014;88:11034-44.

34. Ni L, Ye F, Cheng M-L, et al. Detection of SARS-CoV-2-specific humoral and cellular immunity in COVID-19 convalescent individuals. Immunity 2020;52:971-7.e3.

35. Tay MZ, Poh CM, Rénia L, et al. The trinity of COVID-19: immunity, inflammation and intervention. Nat Rev Immunol 2020;20:363-74.

36. Long Q-X, Tang X-J, Shi Q-L, et al. Clinical and immunological assessment of asymptomatic SARS-CoV-2 infections. Nat Med 2020 June 18 [Epub ahead of print]. doi: 10.1038/s41591-020-0965-6.

37. Kellam P, Barclay W. The dynamics of humoral immune responses following SARS-CoV-2 infection and the potential for reinfection. J Gen Virol 2020 May 20 [Epub ahead of print]. doi: 10.1099/jgv.0.001439.

38. Lin Q, Zhu L, Ni Z, et al. Duration of serum neutralizing antibodies for SARSCoV-2: Lessons from SARS-CoV infection. J Microbiol Immunol Infect 2020 Mar. 25 [Epub ahead of print]. doi: 10.1016/j.jmii.2020.03.015.
39. Cao W-C, Liu W, Zhang P-H, et al. Disappearance of antibodies to SARS-associated coronavirus after recovery. N Engl J Med 2007;357:1162-3.

40. Choe PG, Perera RAPM, Park WB, et al. MERS-CoV antibody responses 1 year after symptom onset, South Korea, 2015. Emerg Infect Dis 2017;23:1079-84.

41. Payne DC, Smith-Jeffcoat SE, Nowak G, et al. SARS-CoV-2 infections and serologic responses from a sample of U.S. Navy service members - USS Theodore Roosevelt, April 2020. MMWR Morb Mortal Wkly Rep 2020;69:714-21.

42. Wölfel R, Corman VM, Guggemos W, et al. Virological assessment of hospitalized patients with COVID-2019. Nature 2020;581:465-9.

43. Atkinson B, Petersen E. SARS-CoV-2 shedding and infectivity. Lancet 2020;395:1339-40.

44. ISDA COVID-19 antibody testing primer. Arlington (VA): Infectious Diseases Society of America; updated 2020 May 4. Available: www.idsociety.org/globalassets /idsa/public-health/covid-19/idsa-covid-19-antibody-testing-primer.pdf (accessed 2020 June 20).

45. Guo L, Ren L, Yang S, et al. Profiling early humoral response to diagnose nove coronavirus disease (COVID-19). Clin Infect Dis 2020 Mar. 21 [Epub ahead of print]. doi: 10.1093/cid/ciaa310.

46. Zhao R, Li M, Song H, et al. Early detection of SARS-CoV-2 antibodies in COVID-19 patients as a serologic marker of infection. Clin Infect Dis 2020 May 1 [Epub ahead of print]. doi: 10.1093/cid/ciaa523.

47. Feldstein LR, Rose EB, Horwitz SM, et al. Multisystem inflammatory syndrome in U.S. children and adolescents. N Engl J Med 2020 June 29 [Epub ahead of print]. doi: 10.1056/NEJMoa2021680.

48. Paediatric inflammatory multisystem syndrome temporally associated with COVID-19 [position statement]. Ottawa: Canadian Paediatric Society; 2020. Available: www.cps.ca/en/documents/position/pims (accessed 2020 July 7).

49. Whittaker E, Bamford A, Kenny J, et al. Clinical characteristics of 58 children with a pediatric inflammatory multisystem syndrome temporally associated with SARS-CoV-2. JAMA 2020 June 8 [Epub ahead of print]. doi: 10.1001/ jama.2020.10369.

50. Multisystem inflammatory syndrome in children and adolescents temporally related to COVID-19 [scientific brief]. Geneva: World Health Organization; 2020 May 15. Available: www.who.int/news-room/commentaries/detail/multisystem -inflammatory-syndrome-in-children-and-adolescents-with-covid-19 (accessed 2020 June 20).

51. National Center for Immunization and Respiratory Diseases (NCIRD). Information for healthcare providers about multisystem inflammatory syndrome in children (MIS-C): case definition for MIS-C. Atlanta: Centers for Disease Control and Prevention; reviewed 2020 May 29. Available: www.cdc.gov/mis-c/hcp/ (accessed 2020 June 15).

52. Toubiana J, Poirault C, Corsia A, et al. Kawasaki-like multisystem inflammatory syndrome in children during the covid-19 pandemic in Paris, France: prospective observational study. BMJ 2020;369:m2094.

53. Belhadjer Z, Méot M, Bajolle F, et al. Acute heart failure in multisystem inflammatory syndrome in children (MIS-C) in the context of global SARS-CoV-2 pandemic. Circulation 2020 May 17 [Epub ahead of print]. doi: 10.1161/CIRCULATIONAHA .120 .048360 .

54. Multisystem inflammatory syndrome in children (MIS-C) associated with coronavirus disease 2019 (COVID-19). Atlanta: Centers for Disease Control and Prevention; 2020. Available: https://emergency.cdc.gov/han/2020/han00432.asp (accessed 2020 July 1).

55. Public health disease management guidelines: multisystem inflammatory syndrome in children (MIS-C). Edmonton: Alberta Government; updated 2020 May 31. Available: https://open.alberta.ca/dataset/7332b06a-515e-4194 -8ffa-a80e4fc0ea3b\#summary (accessed 2020 June 22).

56. Multisystem inflammatory syndrome in children (MIS-C) temporally associated with COVID-19: guidance for clinicians in B.C. Vancouver: BC Centre for Disease Control; 2020. Available: www.bccdc.ca/Health-Professionals-Site/ Documents/COVID19_MIS-C_ClinicianGuidance.pdf (accessed 2020 June 22).

57. COVID-19 - What we know so far about ... Kawasaki disease-like illness. Toronto: Public Health Ontario; 2020. Available: www.publichealthontario. ca/-/media/documents/ncov/covid-wwksf/2020/05/what-we-know-kawasaki -disease-like-illness.pdf?la=en (accessed 2020 June 22).

58. Bermingham WH, Wilding $\mathrm{T}$, Beck S, et al. SARS-CoV-2 serology: Test, test, test, but interpret with caution! Clin Med (Lond) 2020 June 2 [Epub ahead of print]. doi: 10.7861/clinmed.2020-0170. 
Competing interests: Paul Van Caeseele is the director of the Cadham Provincial Public Health Laboratory (Manitoba Health). Mel Krajden has received grants paid to his institution from Roche, Hologica and Siemens. No other competing interests were declared. For competing interests of members of the 5 authorship groups, see Appendix 1 , available at https://www.cmaj.ca/lookup/doi/10.1503/cmaj.201588/ tab-related-content.

This article has been peer reviewed.

Affiliations: Cadham Provincial Public Health Laboratory (Van Caeseele), Winnipeg, Man.; Dynacare (Bailey), Brampton, Ont.; Division of Pediatric Infectious Diseases (Forgie), Department of Pediatrics, University of Alberta, Edmonton, Alta.; Alberta Precision Laboratories (Dingle), Edmonton, Alta.; and Department of Pathology and Laboratory Medicine (Krajden), University of British Columbia, Vancouver, BC.

Contributors: All of the authors contributed to the conception and design of the review; revised the manuscript, which was first drafted by Dana Bailey and Mel Krajden, for important intellectual content; gave final approval of the version to be published; and agreed to be accountable for all aspects of the work. Paul Van Caeseele serves as co-chair of the Canadian Public Health Laboratory Network. Dana Bailey serves as the designated corresponding author for the Canadian Society of Clinical Chemists COVID-19 Significant Interest Working Group. Sarah Forgie serves as president of the Association of Medical Microbiology and Infectious Disease Canada. Tanis Dingle serves as president of the Canadian Association for Clinical Microbiology and Infectious Diseases. Mel Krajden leads the Testing Working Group of the COVID-19 Immunity Task Force.

Members of the Canadian Public Health Laboratory Network: Mike Drebot $\mathrm{PhD}^{\star}$, Jean Longtin $\mathrm{MD}^{\star}$, Tim Booth PhD† (National Microbiology Laboratory); Graham Tipples PhD*, Jamil N. Kanji MD† (Alberta); Inna Sekirov MD PhD*, Muhammad Morshed PhD†, Paul N. Levett PhD DSc $\dagger$ (British Columbia); Paul Van Caeseele MD* (CPHLN corresponding author), Derek Stein PhD† (Manitoba); Richard Garceau MD* (New Brunswick);
Lei Jiao MD PhD* (Newfoundland and Labrador); Todd F. Hatchette MD*, Jason LeBlanc PhD† (Nova Scotia); Julianne Kus PhD*, Jonathan Gubbay MBBS MMedSc† (Ontario); Greg J. German MD PhD†, Jason Robinson $\mathrm{PhD} \dagger$ (Prince Edward Island); Michel Roger MD PhD* (Quebec); Amanda Lang PhD* (Saskatchewan).; *authors; tcontributors.

Members of the Canadian Society of Clinical Chemists (COVID-19 Significant Interest Working Group): authors: Dana Bailey MSc PhD (CSCC corresponding author), Danijela Konforte PhD (CSCC COVID-19 Significant Interest Group chair), Vilte E. Barakauskas PhD, Vathany Kulasingam PhD, Paul M. Yip PhD; contributors: Lori Beach PhD, Ivan Blasutig PhD, Peter Catomeris PhD, Mari L. DeMarco PhD, Yanping Gong MD PhD, Peter A. Kavsak PhD, Ed Randell PhD, Julie Shaw, PhD, Jennifer Taher PhD, Nicole White-Al Habeeb PhD.

Members of the Association of Medical Microbiology and Infectious Disease Canada: author: Sarah E. Forgie MD MEd (AMMI corresponding author); contributors: Isabelle Chiu MD, Yves Longtin MD, LeeAnne M. Luft MD MSc, Shariq Haider MD, Susy Hota MD MSc, Philippe LagaceWiens MD, Kelly MacDonald MD, Andrew Simor MD, Karina Top MD MS, Terence C. Wuerz MD, Deborah Yamamura MD.

Members of the Canadian Association for Clinical Microbiology and Infectious Diseases: authors: Tanis C. Dingle PhD (CACMID corresponding author), Carmen L. Charlton PhD, Samir Patel PhD, Prameet Sheth PhD, Vanessa Tran PhD; contributors: Ramzi Fattouh PhD, Danielle Brabant-Kirwan PhD, Rob Kozak PhD, Chris Lowe MSc MD, Esther Nagai BBA MLS, Valentina Russell BSC MLS.

Members of the COVID-19 Immunity Task Force: authors: Mel Krajden MD (CITF corresponding author), C. David Naylor MD DPhil (editorial coordinator), Timothy G. Evans DPhil MD, Catherine A. Hankins MD, James D. Kellner MD, Allison D. McGeer MD, Caroline Quach-Thanh MD; contributors: James Talbot MD PhD, Gina Ogilvie MD MSc, Vivek Goel MD MSc MS, Scott Halperin MD, Jutta Preiksaitis MD.

Correspondence to: Mel Krajden, Mel.Krajden@bccdc.ca 